\title{
Viagens pedagógicas e o ensino técnico brasileiro (1909-1946)
}

\author{
Olivia Morais de Medeiros Neta* \\ Sandra Maria de Assis** \\ Ísis de Freitas Campos ${ }^{* * *}$
}

\begin{abstract}
Resumo
O objetivo deste texto é inventariar viagens pedagógicas ao exterior financiadas com participação do governo brasileiro, com finalidades relativas à estruturação do ensino técnico brasileiro de 1909 a 1946, a partir do que foi encontrado na historiografia sobre o assunto. Os marcos temporais referem-se à implantação da Escola de Aprendizes Artífices e da Comissão Brasileiro-Americana de Educação Industrial, importantes na sistematização do ensino técnico nacional. O conceito de viagens pedagógicas corrobora para a pesquisa bibliográfica e documental, principalmente em jornais da época - por meio da Hemeroteca Digital Brasileira-, mas também em outras fontes como correspondências e fotografias. Foram inventariadas viagens à Europa e América com propósito de participação em eventos temáticos, como o Congresso Internacional de Ensino Profissional realizado em Roma, em 1936, e/ou de visitas técnicas, como à Alemanha, França, Suíça e Estados Unidos da América, além de sondagens e de efetiva concretização de contratações. Procurou-se destacar os viajantes, o contexto e duração da missão e as repercussões já constatadas na historiografia. Algumas tiveram uma maior elucidação a partir de consultas a fontes do período. $O$ estudo contribui com o campo da história da educação profissional, asseverando a circulação de ideias e modelos para o ensino técnico no Brasil.
\end{abstract}

\section{Palavras chave \\ Viagens pedagógicas, ensino técnico, intelectuais, Brasil.}

Recepció original: 31 de març de 2021

Acceptació: 2 de maig de 2021

Publicació: 1 de juliol de 2021

\section{Introdução}

No Brasil, durante a Primeira República (1889-1930), o sistema escolar brasileiro e, notadamente, a educação profissional adquiriram nova configuração, como observa Manfredi (2002). O que antes resumia-se a umas poucas instituições dedicadas ao ensino de ofícios artesanais e manufatureiros destinadas a atender aos pobres e desvalidos (em geral órfãos), deu lugar a um conjunto de escolas mantidas pelo poder público (estadual e federal), mas também por outras entidades, como a lgreja Católica e associações de trabalhadores, por exemplo.

A montagem e organização de tais escolas, além de atender seu público anterior, digo, crianças pobres e filhos de trabalhadores, também teriam um propósito que se

$\left({ }^{*}\right)$ Professora da Universidade Federal do Rio Grande do Norte (Brasil). Correio eletrônico: olivianeta@gmail.com

(**) Professora do Instituto Federal de Educação, Ciência e Tecnologia do Rio Grande do Norte (Brasil). Correio eletrônico: sandra.assis@ifrn.edu.br

${ }^{(* * *)}$ Estudiante do Pós-graduação em educação da Universidade Federal do Rio Grande do Norte (Brasil). Correio eletrônico: isiscampus@gmail.com 
coadunava com os interesses da república positivista: acelerar os processos de industrialização e urbanização iniciados, com algumas ressalvas visto que não alcançava todas as regiões do país, no período imperial. Ao encontro disso, e,

\begin{abstract}
sob inspiração do ideário positivista de formação para o trabalho, já havia uma institucionalização da qualificação e do disciplinamento laboral dos setores populares. Ademais, as mudanças socioeconômicas que ocorriam à medida que o projeto republicano avançava, a expansão da economia cafeeira, o projeto de atração de imigrantes europeus e as consequências da abolição da escravidão já apresentavam impactos na urbanização e até mesmo na formação das primeiras metrópoles brasileiras. Nesse sentido, formar para o trabalho era uma necessidade econômica, política e social. (Pedrosa e Santos, 2014, p. 315)
\end{abstract}

Nesse contexto, pelo Decreto 7.566, 19 escolas foram criadas em cada unidade da federação, com exceção do Distrito Federal e do Rio Grande do Sul. Tais instituições tinham como objetivo educacional a preparação de Nesse contexto, pelo Decreto 7.566, 19 escolas foram criadas em cada unidade da federação, com exceção do Distrito Federal e do Rio Grande do Sul. Tais instituições tinham como objetivo educacional a preparação de «operários e contramestres, por meio do ensino prático e de conhecimentos técnicos transmitidos aos menores em oficinas de trabalhos manuais ou mecânicos mais convenientes e necessários ao Estado da Federação» (Manfredi, 2002, p. 83). Sendo assim, viu-se o governo Nilo Peçanha «transformar as escolas de aprendizes num único sistema [...] como resposta a desafios de ordem econômica e política» (Manfredi, 2002, p. 82).

Nesse processo de organização do ensino técnico brasileiro, Cunha (2012) destaca a intenção brasileira em procurar no exterior elementos que pudessem contribuir com o desenvolvimento de um campo que no Brasil era ainda incipiente. Esses elementos podem ser considerados aqui tanto a nível de acordos quanto da percepção do funcionamento nas experiências estrangeiras.

Considerando esse contexto, o objetivo deste texto é inventariar, a partir de pesquisa bibliográfica e documental, viagens pedagógicas ao exterior financiadas pelo governo brasileiro com finalidades relativas à estruturação do ensino técnico brasileiro, àquele momento visto como essencial à modernização do país. O recorte inicial, 1909, refere-se à referida sistematização das Escolas de Aprendizes Artífices e o final, 1946, à criação da Comissão Brasileira-Americana de Ensino Industrial (CBAI), quando se passou a sistematizar as viagens de aperfeiçoamento dos profissionais brasileiros do ensino industrial a partir de um acordo entre o Brasil e os Estados Unidos.

Assim, partiu-se do entendimento que as viagens pedagógicas referentes ao ensino profissional brasileiro «educam, mesmo que seja para abrir ao viajante uma realidade diferente da sua. Mas umas educam mais que outras, ou de forma diferente» (Viñao Frago, 2007, p. 16). No entanto, algumas são mais representativas para a compreensão desses processos, podendo ser entendidas como viagens pedagógicas.

Considera-se neste texto a amplitude do conceito de viagens pedagógicas elaborado por Viñao Frago (2007), que abarca aquelas que se deram por iniciativa própria, por missão governamental e, até mesmo, as que aconteceram em situação de exílio. Mas, neste caso, serão consideradas apenas viagens ao estrangeiro promovidas com participação governamental, na busca por referências para o ensino técnico a ser oferecido no Brasil, de uma forma que atendesse às demandas socioeconômicas e políticas do país. 
Para a seleção dessas missões, buscou-se pinçar contribuições da historiografia da área e averiguar, a partir de visita a fontes, elementos que ampliassem o entendimento sobre essas viagens. Nesse sentido, a procura nos jornais da época, a partir da Hemeroteca Digital Brasileira, foi elemento importante para a localização dos viajantes em suas chegadas e partidas e mesmo com relação aos objetivos e resultados das viagens. Ademais, fotografias e escritos dos agentes foram utilizados nesta investigação.

Foram consideradas nesse processo missões com finalidade de visitas para conhecer a experiência dos outros países, de sondagens para contratação de funcionários e de participação em eventos. Vale ressaltar que não se intenciona aprofundar sobre o impacto que essas viagens tiveram no ensino técnico, mas expor as possibilidades de investigação a partir da sistematização do que se sabe até então.

\section{Viagens, viajantes e o Ensino Técnico}

O trajeto que se planeja seguir neste trabalho começa com as viagens de João Luderitz. A partir do funcionamento satisfatório do Instituto Parobé, credenciado como Escola de Aprendizes Artífices do Rio Grande do Sul em 1918, o engenheiro passou a chefiar o Serviço de Remodelação do Ensino Profissional Técnico, de 1921, cujo objetivo era de examinar o funcionamento das Escolas de Aprendizes Artífices e remodelar o ensino profissional, tornando-o mais eficiente, racional e moderno, conforme Fonseca (1961).

Pedrosa e Santos (2014) destacam a relevância do então diretor do Instituto Técnico Profissional ${ }^{1}$, fundado em 1906 como uma instituição da Escola de Engenharia, na busca de referências no estrangeiro para o desenvolvimento do ensino profissional brasileiro. Vale considerar que «apesar de ser fundada como instituição privada e continuar assim durante mais de trinta anos, a instituição era considerada de propriedade pública por ter servido à comunidade '[...] porque os fundadores nenhum provento ou direito exclusivo, estabeleceram para si [...]'» (Silva, 2013, p. 4). Os recursos financeiros para fundação foram adquiridos através de doações e auxílios do poder público, recebendo auxílio tanto do governo estadual, quanto nacional.

Além da motivação de compra de materiais para a Escola de Engenharia,

\footnotetext{
Em 1909, Luderitz viajava à Europa e aos Estados Unidos com a missão de contratar mestres para as oficinas, como também visitar escolas que pudessem servir como modelo de ensino técnico a ser aplicado no Instituto Parobé, onde atuava como Diretor. Após essa viagem, foram contratados até 1920 técnicos de origem inglesa, alemã e italiana. (Queluz, 2000, p. 142)
}

Luderitz visitou, de janeiro a setembro, Alemanha, Inglaterra, França, Bélgica, Suíça, Itália, e de lá os Estados Unidos. Sobre a experiência, Luderitz escreveu um relatório apresentado à Escola de Engenharia². Durante essa viagem, Luderitz visitou a Escola de Charleroi (na Bélgica), dirigida por Omer Buyse, a qual passaria a se tornar um referencial para a Escola de Engenharia. Machado (2010) destaca a posterior presença do engenheiro belga na educação profissional brasileira, desde a tradução em 1925 por Anísio Teixeira de Méthodes américaines d'ecucation genérale et technique, de 1913, até a elaboração por Buyse do anteprojeto da Universidade do Trabalho em 1934. Nas discussões

(1) A partir de 1915, Instituto Parobé. Luderitz chefiou a instituição de 1908 a 1921.

(2) Varias. A Federação: Órgão do Partido Republicano. Porto Alegre. 6 abr 1911. Disponível em: http://memoria.bn.br/DocReader/DocReader.aspx?bib=388653\&pesq=Luderitz\&pasta=ano\%20192\&pagfis $=23907$ [Acesso em 20 nov. 2020]. 
para esse projeto, inclusive, formou-se uma comissão da qual Luderitz foi membro. Tais elementos evidenciam a relação entre as missões de Luderitz e as ideias que circularam nas décadas posteriores, tendo implicações a nível nacional.

Acrescente-se que, como destaca Amorim (2004), em 1910 o intelectual promoveu uma reforma no Instituto Técnico-Profissional para adaptar os alunos ao ambiente fabril, buscando formação mais rápida possível e enfatizando disciplinas de caráter técnico-científico em detrimento das de cultura geral, aos moldes do taylorismo.

Já em janeiro de 1912, Luderitz e sua esposa viajaram com o propósito de passar um ano na Europa e Estados Unidos - ocasião em que atualizaram o endereço para Paris ${ }^{3}$. No começo do referido mês, o periódico consultado havia anunciado a viagem somente à Europa pontuando como objetivo, na condição de chefe da Escola de Engenharia, a visita à cultura do trigo e estudo dos meios de fundar uma escola experimental em Porto Alegre. ${ }^{4}$

Outrossim, a viagem proporcionou a Luderitz firmar determinados vínculos com o exterior, já que durante a missão, em março de 1912, foi nomeado cônsul da Bélgica ${ }^{5}-$ posto que ocupou até $1915 .{ }^{6}$ Foi também no ano dessa missão que os três primeiros alunos formados no Instituto Parobé viajaram a fim de fazer cursos de especialização na Alemanha e Estados Unidos, passando, no regresso, a constituir o corpo de professores da instituição7, o que, como destaca Silva (2013), era um processo para substituição do quadro de professores em boa parte estrangeiros da instituição.

Por conta das suas viagens, Luderitz tentou trazer para o Brasil os exemplos de uma educação profissional que atendesse às necessidades da indústria, assim antecipando o que viria após 1930. A esse respeito, Machado (2010) afirma que a gestão de Gustavo Capanema no que se refere à reorganização do ensino industrial seguiu, inicialmente, os mesmos passos de Luderitz, inclusive com a continuidade das viagens para visitas às escolas europeias e americanas. Na década seguinte, Luderitz ocupou o cargo de diretor nacional do SENAI (1942-1948), o que demonstra seu prestígio e influência nesse setor.

Outro viajante mencionado é Roberto Mange. O educador e engenheiro suíço, formação na Suíça com complementação em países europeus como a Alemanha, chegou

(3) Despedida. A Federação: Orgam do Partido Republicano. Porto Alegre. 22 jan 1912. Disponível em: http://memoria.bn.br/DocReader/DocReader.aspx?bib=388653\&pesq=Luderitz\&p<asta=ano\%20192\&pagfi $\mathrm{s}=24943$ [Acesso em 20 nov. 2020].

(4) Varias. A Federação: Orgam do Partido Republicano. Porto Alegre. 9 jan 1912. Disponível em: http://memoria.bn.br/DocReader/DocReader.aspx?bib=388653\&pesq=Luderitz\&pasta=ano\%20192\&pagfis $=24901$ [Acesso em 20 nov. 2020].

(5) Varias. A Federação: Orgam do Partido Republicano. Porto Alegre. 23 mar 1912. Disponível em: http://memoria.bn.br/DocReader/DocReader.aspx?bib=388653\&pesq=Luderitz\&pasta=ano\%20192\&pagfis $=25155$ [Acesso em 20 nov. 2020].

(6) Varias. A Federação: Orgam do Partido Republicano. Porto Alegre. 3 mar 1915. Disponível em: http://memoria.bn.br/DocReader/DocReader.aspx?bib=388653\&pesq=Luderitz\&pasta=ano\%20192\&pagfis $=31498$ [Acesso em 20 nov. 2020].

(7) Ver mais em: https://www.cteparobe.com.br/pagina/78_Historia-da-Cidade.html [Acesso em 20 nov. 2020]. 
ao Brasil em 1913 para trabalhar na Escola Politécnica da Universidade de São Paulo. Mange ocupou vários cargos importantes em instituições de ensino profissional ${ }^{8}$.

Na perspectiva de atender às necessidades de mão de obra qualificada e especializada para as ferrovias, estas mesmas patrocinavam, com apoio financeiro do Ministério da Agricultura, Indústria e Comércio, os cursos de formação, enviando para estes seus melhores aprendizes. Daí nasceu a iniciativa de criar os Centros Ferroviários de Ensino e Seleção Profissional.

Roberto Mange, na condição de seu representante do Liceu de Artes e Ofícios, realizou em 1929, conforme Cunha (2000), viagem à Alemanha, «para estudar o processo de aprendizagem dos operários das ferrovias desse país, aplicando os conhecimentos adquiridos nas experiências que posteriormente orientou nas companhias de estradas de ferro de São Paulo» (Cunha, 2000, p. 132). Nesse sentido, em 1930, um ano depois, portanto, Mange participou da montagem e estruturação do Serviço de Ensino e Seleção Profissional da Estrada de Ferro Sorocaba, da qual foi diretor até 1934.

Conforme Oliveira (2013) e Boschetti (2006), as práticas educativas no espaço escolar do Curso de Ferroviários procuravam mobilizar e impor um modelo profissional alinhado com as estruturas socioeconômicas capitalistas. Estas estruturas estavam invariavelmente definidas por uma rigorosa divisão social do trabalho, ou seja, a divisão entre o trabalho manual e o trabalho intelectual. Roberto Mange defendia os métodos dos Centros Ferroviários de Ensino e Seleção Profissional, baseados na psicotécnica, na separação entre o espaço operário da fábrica e os espaços dos aprendizes no uso das séries metódicas, em substituição à presença de um mestre instrutor. Ele queria evitar que os aprendizes copiassem processos defeituosos ou herdassem os vícios preexistentes.

Mange participou da formulação de políticas educacionais e, ao que parece, tinha um bom trânsito nos ministérios da Educação e do Trabalho fazendo, algumas vezes, a conexão entre os empresários da indústria e o governo, como também entre os que pensavam as políticas para a educação profissional, tendo sido um dos membros da comissão que elaborou o Decreto que criou o Senai. Além disso, foi o seu primeiro diretor no Estado de São Paulo. O nome de Mange ainda constará em viagens sobre o ensino profissional registradas neste texto, sendo então para atender a demandas mais amplas do ensino profissional.

Com a chegada da Era Vargas, o Brasil passa por uma modificação administrativa em vista a uma centralização, simbolizada, neste caso, pela constituição do Ministério da Educação e Saúde. Nesse sentido, as ações em torno do ensino profissional ganham uma costura mais estruturada.

Dentro desse contexto, de acordo com Pedrosa (2015), o período de 1934 a 1942 correspondeu a um grande esforço para a constituição, do que ficou conhecido como novo ensino industrial brasileiro, e que tal processo demandou muito trabalho dos agentes do ensino industrial. Esses homens (e aqui vale destacar a prevalência masculi-

(8) Mange esteve à frente dos cursos desenvolvidos na Escola Profissional Mecânica do Liceu de Artes e Ofícios de São Paulo e dirigiu o Serviço de Ensino e Seleção Profissional da Estrada de Ferro Sorocabana. Ver Pedrosa e Santos (2014). 
na), conforme Pedrosa (2015), atuaram nesse processo nas diferentes comissões constituídas pelo governo de Vagas.

\begin{abstract}
O mapeamento realizado indica que alguns agentes tiveram participação destacada nesse processo constituinte, seja assessorando, elaborando projetos seja participando dos grupos de trabalho ou das reuniões de negociação: Celso Suckow da Fonseca, Francisco Belmonte de Montojos, Horácio Augusto da Silveira, João Lüderitz, Joaquim Faria Góes Filho, Leon Renault, Licério Alfredo Schreiner, Manuel Bergström Lourenço Filho, Robert Auguste Edmond Mange, Roberto Cochrane Simonsen e Rodolfo Fuchs. (Pedrosa, 2015, p. 15)
\end{abstract}

Este texto enfatiza o papel desses agentes, para além dessas funções, na construção de vínculos entre o Brasil e o exterior no desenvolvimento do ensino profissional.

Ainda com relação a esse novo momento para o ensino profissional, Schwartzman et al (2000) aponta discussões em 1935 entre Vargas e Capanema sobre a contratação de professores estrangeiros para o ensino industrial. $O$ acordo presidencial constitui um marco importante, já que estabeleceu a orientação para sondagens realizadas nos países a partir das viagens que fossem feitas à Europa. Schwartzman et al (2000) ainda ressalta um documento da mesma época em que Rodolfo Fuchs, da Divisão de Ensino Industrial, apontava sugestões de mestres estrangeiros para os liceus nacionais.

O teuto-brasileiro Rodolfo Fuchs, aliás, foi outro agente ligado ao ensino profissional a visitar outros países a fim de conhecer seus modelos de ensino. Depois de algumas viagens, em 1935 escreveu um relatório apontando a necessidade de treinamento racional e metódico, observando o exemplo dos operários da Ford, nos EUA. Pedrosa e Santos (2014) destacam ainda que Fuchs considerou nesse trabalho a ideia da obrigatoriedade da habilitação profissional.

Outro intelectual que precisa ser mencionado no contexto da influência de suas viagens ao ensino profissional é Manuel Bergstron Lourenço Filho. Pedrosa e Santos (2014) destacam que, dos signatários do manifesto de 1932, apenas ele continuou atuante nas discussões acerca do ensino profissional, além de ter participado da fundação do ldort (1931), que influenciou o ensino industrial em todo o país.

Por enquanto, considera-se sua missão de 1935, aos Estados Unidos sob supervisão de Anísio Teixeira, diretor de Instrução Pública do Rio de Janeiro, a fim de conhecer seu sistema educacional. Pedrosa e Duenhas (2019) apontam que o intelectual esteve nos primeiros meses do referido ano nos EUA e, junto ao professor Delgado de Carvalho e a Carneiro Leão, compareceu aos Congressos Anual e Nacional de Educação em Atlantic City e New Jersey, além de participar de aulas, encontros e conversas técnicas.

\footnotetext{
Participou de aulas, teve encontros e conversas técnicas e realizou observações e durante o mês que passou em Nova York em atividades junto aos professores do Teachers College. (WARDE, 2003). Produziu relatos que foram enviados ao seu chefe Anísio Teixeira detalhando o que estava compreendendo daquele momento anglo-americano como o regime social e a filosofia de vida, a cultura do individualismo, a especialização precoce, o capitalismo, além da economia dirigida que conduzia à centralização. Em termos educacionais observou que havia a ideia do controle estatal em relação às taxas para melhor distribuição de fundos, mas também que havia uma longa distância, na maioria das escolas, entre as teorias educacionais e a prática e, ainda, que as escolas estavam cuidando de formar os professores com maior cultura geral, além do aprendizado técnico. (Pedrosa e Duenhas, 2019, p. 3)
}

Outrossim, mesmo profissionais que não estavam diretamente ligados ao ensino profissional tiveram suas viagens direcionadas para experiências também sobre esse 
setor. Em 1936, Antônio de Sá Pereira9 ${ }^{9}$, membro do Instituto Nacional de Música, viajou a Praga para participar do Congresso de Educação Musical ${ }^{10}$, ocorrido no mês de abril, ${ }^{11}$ mas depois seguiu para Berlim, já que «o ensino profissional era um dos 10 pontos a serem investigados por Sá Pereira, junto ao Aussenpolitisches Amt, a secção dos negócios estrangeiros do partido nacional-socialista» (Machado, 2010, p. 57).

Cunha (2012) aponta que a expectativa brasileira era a de negociar a contratação de estrangeiros para o ensino profissional brasileiro (ideia que parece ter partido do próprio Capanema), mas os alemães consideraram que seria melhor que um de seus especialistas fosse apontar melhorias no ensino profissional brasileiro.

Sá Pereira enviou uma carta informando sobre a proposta alemã e em resposta foi montada uma comissão para analisá-la, sob chefia de Leon Renault. A conclusão foi que estrangeiros não conseguiriam compreender as necessidades brasileiras e optou-se por enviar brasileiros para analisar a educação alemã. Para Machado (2010)

uma área específica do sistema alemão despertou o interesse da comissão - o departamento de aconseIhamento ao adolescente, onde estes receberiam orientação sobre suas carreiras, além de estabelecer limites para matrículas nas áreas que estivessem sobrecarregadas, inclusive no ensino universitário. (Machado, 2010, p. 59)

Ainda, estipulou-se, conforme Cunha (2012), a contratação de 30 profissionais de vários países, conforme as especialidades, sendo eles: Alemanha (marcenaria, fototécnica, litografia, ajustagem mecânica, indústrias químicas -adubos, explosivos, inseticidas, fungicidas, tintas, esmaltes, vernizes, matérias graxas e produtos farmacêuticos-, couros e peles), França (encadernação artística, cinzelagem, fundição artística, decoração de interiores, cerâmica, avicultura), Suíça (mecânica de precisão, laticínios), Itália (apicultura, sericultura e vitivinicultura), Espanha (cantaria e estatuária), Portugal (horticultura) e Estados Unidos (eletrotécnica).

Sá Pereira ainda estava na Alemanha quando a resposta da comissão foi enviada, um mês depois, mas Cunha (2012) não teve acesso à resposta em suas investigações. Ainda, em junho, o agente continuava colhendo dados sobre o sistema educacional alemão, como informou Villa-Lobos em uma entrevista ${ }^{12}$.

$\mathrm{Na}$ verdade, o viajante permaneceu em Berlim ainda por um longo tempo. Suas obrigações eram «tantas», como escreveu no verso de uma fotografia mais descontraída enviada à mãe (Figura 1) em outubro de 1936, informando que em breve deixaria a cidade «(com muitas saudades, é claro)» e estaria de volta em novembro. O documento traz a dimensão do lazer que poderia estar envolvida nessas missões para seus viajantes.

(9) Sá Pereira já tinha experiências na Alemanha, tendo estudado desde os 12 anos de idade em suas instituições escolares.

(10) Para esse congresso também era esperado Villa Lobos, que chegou quando o evento já tinha acabado por causa de um atraso no Zeppelin.

(11) O Congresso de Educação Musical em Praga. Diário Carioca. Rio de Janeiro. 29 abr. 1936. Disponível em: http://memoria.bn.br/DocReader/DocReader.aspx?bib=093092_02\&pesq=\%22Congresso\%20de\%20Educa \%C3\%A7\%C3\%A30\%20Musical\%22\&pasta=ano\%20193\&pagfis=24464 [Acesso em 22 nov. 2020].

(12) Teve Completo Êxito a Missão de Villa Lobos na Europa. Diario Carioca. Rio de Janeiro: 17 jun 1936. http://memoria.bn.br/DocReader/DocReader.aspx?bib=093092_02\&pesq=\%22Congresso\%20de\%20Educa \%C3\%A7\%C3\%A30\%20Musical\%22\&pasta=ano\%20193\&pagfis=25189 [Acesso em 22 nov. 2020]. 


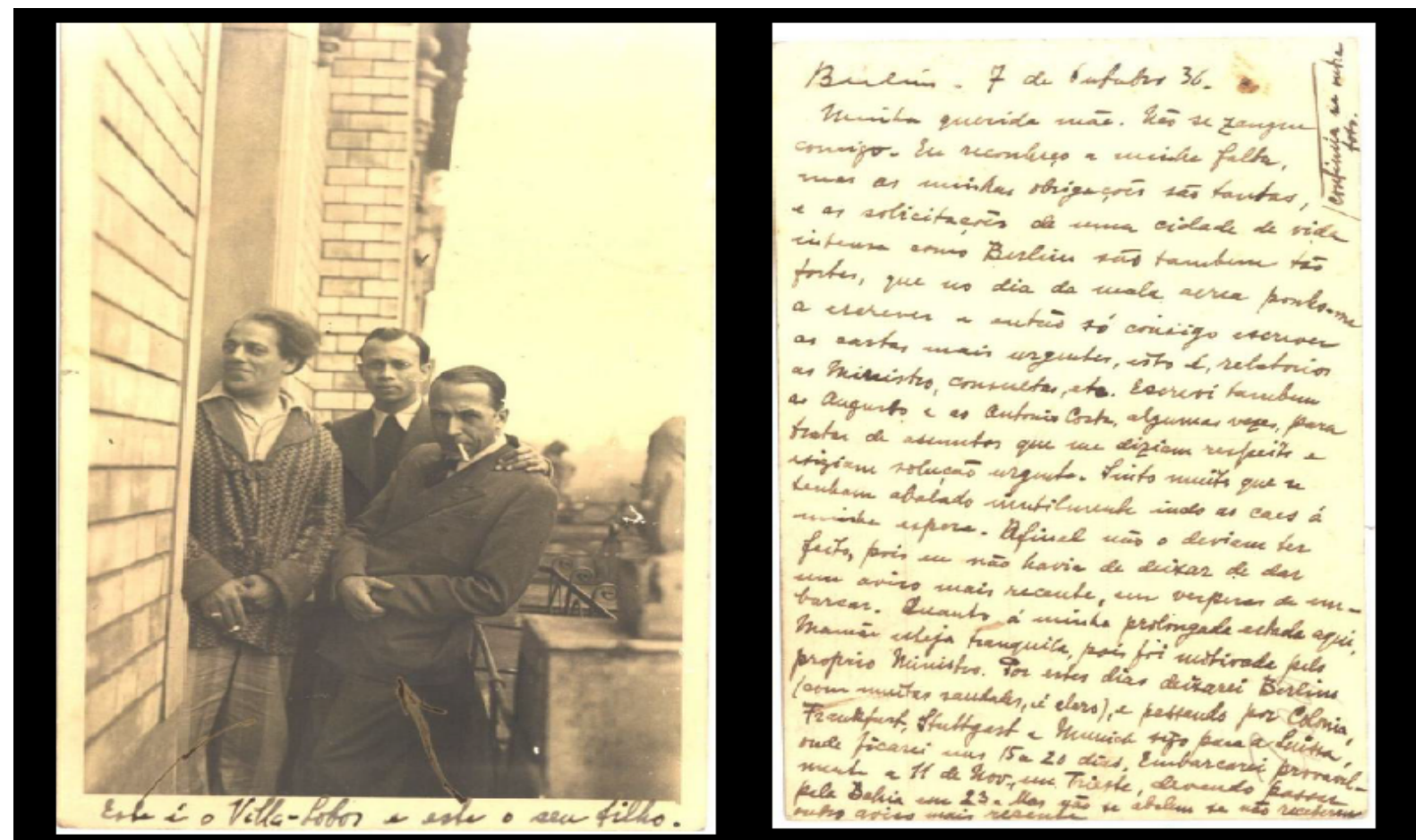

Fonte: Antônio Leal de Sá Pereira. Disponível em:

http://www.escolasapereira.com.br/arquivos/Antonio_Sa_Pereira.pdf_Acesso em 25 ago. 2020].

Para além das missões cujo objetivo era observar o ensino no estrangeiro e sondar a contratação de profissionais, houve as que se destinavam também ao comparecimento em conferências sobre o ensino profissional. No mesmo ano de 1936, mas em dezembro, Lourenço Filho, Francisco Montojos, (inspetor do Ensino Profissional e Técnico), ${ }^{13} \mathrm{e}$ León Renault (então diretor do Instituto João Pinheiro, Belo Horizonte, representante de Minas no ensino técnico) participaram, em Roma (Itália), do Congresso Internacional de Ensino Profissional (ver Figura 2), quarto organizado pelo Bureau International de l'enseignement technique e ao qual o governo brasileiro foi convidado a comparecer. Conforme Machado,

A Superintendência do Ensino Industrial indicou os nomes de João Luderitz, Horácio da Silveira, Leon Renault, Isaias Alves, Nereu Sampaio, Rodolfo Fuchs e o próprio Superintendente Francisco Montojos. Ao encaminhar o assunto ao Presidente da República, Capanema destaca a importância de o Brasil enviar representantes 'escolhidos dentre pessoas devotadas ao assunto, possuidoras de longa experiência e boa cultura'. O Ministro afirmou ainda que o momento seria oportuno para contratar 'professores estrangeiros' do ensino profissional, para a realização de 'cursos práticos e teóricos' aos professores locais, 'questão que se apresentava como inadiável'. (Machado, 2010, p. 55)

A participação seria útil ainda para «[...] aprofundar os estudos sobre o tema nos países europeus, sendo benéfico para a elaboração do 'Plano Nacional da Educação' no Brasil» (Machado, 2010, p. 54). E, embora fosse declarada a intenção, não houve contratação nesse momento, mas a viagem foi utilizada para sondagens em outros países.

(13) Cargo que exerceu de 1927 a 1949, conforme Pedrosa e Santos (2014). 


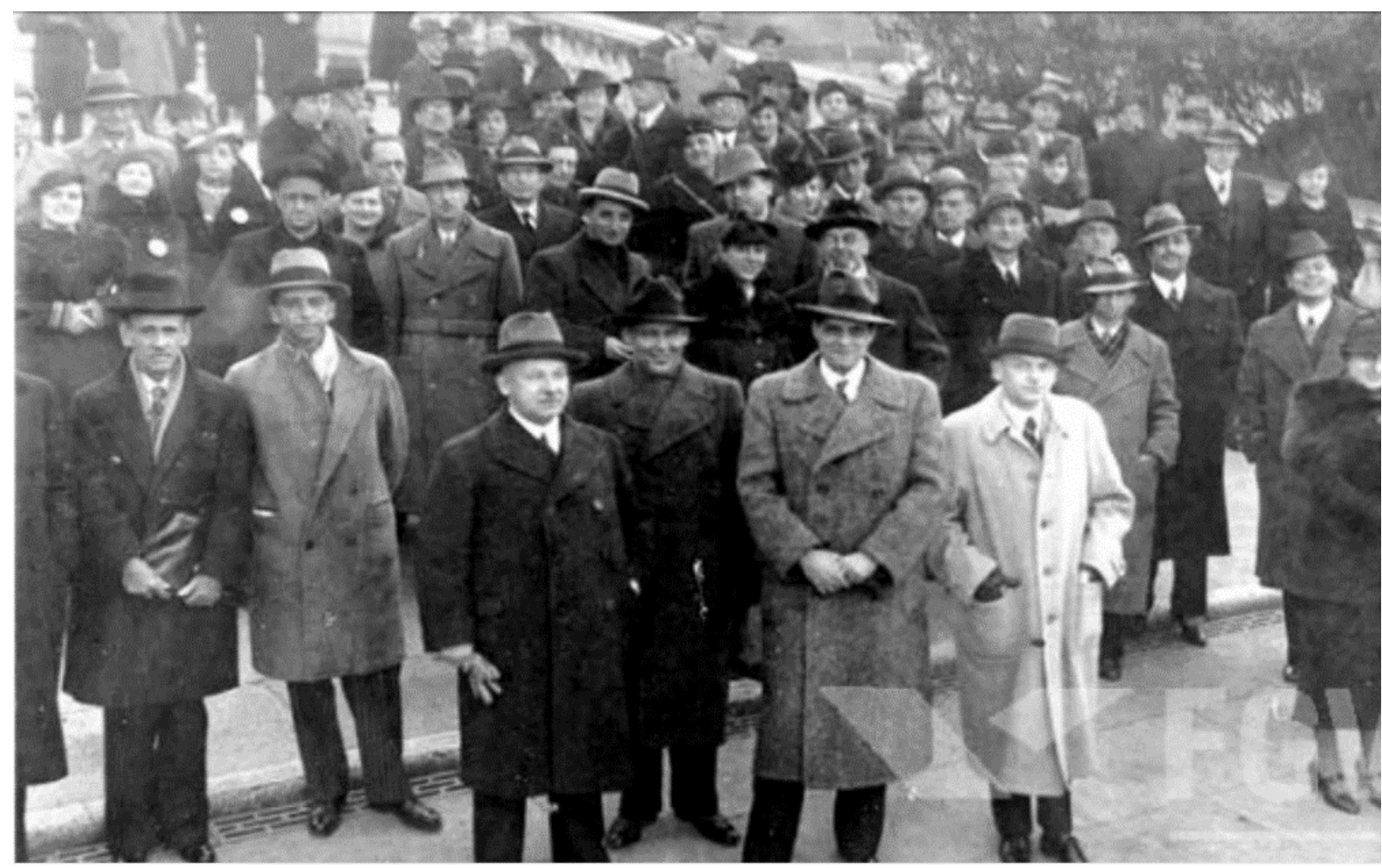

Fonte: Machado (2010).

Em fevereiro de 1937, quando já estava de volta da Europa, Leon Renault fez uma fala aos Diários Associados sobre o evento ${ }^{14}$. Das teses debatidas, $O$ ensino técnico e a vida econômica e $A$ preparação da mulher para o desempenho de uma vida especial na vida econômica tiveram como relator Renault; $A$ orientação profissional e sua continuidade ficou por conta de Lourenço Filho e A formação do pessoal da oficina encarregado do ensino prático nos estabelecimentos técnicos, por Montojos. Na entrevista, Renault ainda destacou o panorama do ensino profissional da Itália.

Mais tarde, em um texto produzido por Francisco Montojos e divulgado no Boletim da CBAI de 1948, o intelectual, defendendo a necessidade de os professores terem experiência profissional na indústria -para além da formação teórica-, retoma recomendações do Congresso de 1936. Montojos aponta que nesse evento se considerou a importância da recrutação de professores dentre os que possuíssem experiência na indústria, sendo dada uma formação pedagógica. $O$ autor ressalta que não se pode «copiar, sempre, o que se faz no estrangeiro. Mas, como país novo, não pode o Brasil deixar de aproveitar a experiência dos outros países mais adiantados» (Boletim da CBAI, n. 10, 1948, p. 147), acrescentando que em países como Estados Unidos, Alemanha, Bélgica, Suíça e Holanda os professores precisam passar por um estágio com duração de 4 a 10 anos antes de ingressar no magistério. É notória, portanto, a persistência das ideias que circularam no evento e mais de uma década depois continuam a legitimar argumentações sobre o ensino técnico no Brasil.

(14) O Brasil e o Congresso Internacional do Ensino Technico. O Jornal. Rio de Janeiro: 5 fev 1937. http://memoria.bn.br/DocReader/DocReader.aspx?bib=110523_03\&pesq=\%22Leon\%20Renault\%22\&pasta $=$ ano\%20193\&pagfis=35871 [Acesso em 22 nov. 2020]. 
Já no ano de 1938, Rodolfo Fuchs, então Inspetor Regional do Ensino Industrial do Ministério da Educação no Nordeste, participou do v Congresso Internacional do Ensino Profissional, em Berlim (Alemanha), realizado entre 23 e 29 de julho.

Segundo Machado, o teuto-brasileiro era muito próximo ao Ministro Capanema e,

Apesar de Francisco Montojos, Diretor do Ensino Industrial, sugerir o envio do Engenheiro Licério Schreiner, técnico daquela divisão, como representante brasileiro no Congresso, Gustavo Capanema encaminhou ao Presidente os nomes de Nereu Sampaio e Rodolfo Fuchs, sendo este último o escolhido. (Machado, 2010, p. 53)

A viagem de Fuchs foi narrada pelo Jornal do Brasil do dia 15 de julho ${ }^{15}$ como um tanto atribulada. Ele partiu no navio Neptunia quando este passou por Recife, última escala sul-americana, depois de ter se atrasado para pegá-lo no Rio de Janeiro, tendo que ir desse local a Recife em um avião. $O$ periódico também anunciou que o viajante ficaria na Europa pelo espaço de 2 a 3 meses, devendo visitar outros países, além da Alemanha.

Em fala aos Diário Associados, Fuchs (1938) destacou que «as viagens dos grandes transatlânticos levam, no mínimo, de 12 a 13 dias, do Rio a Hamburgo» e, podendo apenas contar com um navio que fazia Nápoles-Rio em 13 dias, acabou chegando um dia depois do começo do Congresso.

Cunha (2012) destaca que «além de participar do congresso, Fuchs visitou instituições de educação profissional na Alemanha e na França. Anexo ao relatório de sua viagem, o ministro recebeu o texto intitulado $O$ ensino profissional na Alemanha 1938, redigido por Fuchs, com 72 páginas» (p. 386). Ademais,

Três anos depois de enviado ao ministro, o relatório de Fuchs sobre o ensino profissional na Alemanha foi publicado em três números de Formação - Revista Brasileira de Educação, editada no Rio de Janeiro, de março a maio de 1941. O texto sofreu pequena revisão formal, mas foi acrescentada nota que diz ter sido ele apresentado no v Congresso Internacional de Ensino Profissional em Berlim. Isso não é verdadeiro, pois o autor disse, em carta a Capanema, que não havia levado nenhuma tese, limitando-se a assistir aos trabalhos do evento. (Cunha, 2012, p. 389)

O escrito constituiu-se a defesa pelo modelo da oficina-escola, alemão, em detrimento da escola-oficina, francês. Os modelos estavam em disputa no começo da década de 1940, inclusive pelo Ministério do Trabalho (modelo alemão) e da Educação (francês), como também observa o autor.

Em 1938, conforme Pedrosa e Santos (2014), «foi formada comissão composta por Roberto Mange, Lourenço Filho, León Renault, Góes Filho, Horácio da Silveira, Francisco Montojos e Rodolfo Fuchs para fazer um levantamento dos problemas relativos ao ensino industrial brasileiro» (pp. 226-227). Produziu-se um documento intitulado Lei Criando a Comissão do Plano Geral do Ensino Profissional, no qual os resultados da participação nos congressos são evidenciados:

Ainda é pensamento aproveitar o futuro plano, os resultados dos Congressos Internacionais do Ensino Profissional, realizados em Roma e Berlim, e as observações feitas pelos Delegados brasileiros que compareceram aos mesmos, sobre a organização que os países mais avançados da Europa deram, durante os últimos anos, ao ensino profissional (Pedrosa e Santos, 2014, p. 327)

(15) Perdendo o navio no Rio, alcançou-o em Recife. Jornal do Brasil. Rio de Janeiro: 15 jul 1938.

http://memoria.bn.br/DocReader/DocReader.aspx?bib=030015_05\&pesq=\%22Rodolfo\%20Fuchs\%22\&pasta=an o\%20193\&pagfis=85765 [Acesso em 20 nov. 2020]. 
Outro evento, em 1939, embora promovido com o objetivo de discussão mais ampla sobre o mundo do trabalho, merece menção. A xxv Conferência Internacional do Trabalho aconteceu em Genebra, na Suíça, e teve, segundo Fonseca (1961), dentre os seus participantes brasileiros Francisco Montojos (Diretor do Ensino Técnico Profissional do Ministério da Educação e Saúde Pública) e Oscar Saraiva (Procurador do Departamento Nacional do Trabalho) como representantes na Comissão de Ensino Técnico respectivamente representando o governo e os empresários, como previa a estrutura do evento.

Em suas considerações sobre essa reunião, Celso Suchow da Fonseca (1961) registrou que Montojos expôs que a legislação brasileira estava adiantada, contendo até mesmo elementos que ainda eram objeto de sugestão pelo evento. No entanto, pontuou que, com relação à aprendizagem, ainda se tinha que adiantar no Brasil, tendo o exemplo das oficinas-escola em Pernambuco, organizadas por Fuchs, mas sendo necessário haver um plano para todo o país.

Pronko (2003) considera que as Recomendações resultantes da Conferência, uma relativa à formação profissional ( $\left.n^{\circ} 57\right)$ e outra à aprendizagem ( $\left.n^{\circ} 60\right)$,

não representaram grandes novidades no panorama da época. Talvez tenham reforçado a posição dos empresários industriais, alentando um tipo de instituição para encaminhamento da aprendizagem no modelo do que, alguns anos mais tarde, seria o SENAI. (Pronko, 2003, p. 8)

Em dezembro de 1940, Roberto Mange, que atuava na Escola Politécnica da Universidade de São Paulo, como professor de Mecânica, viajou à Europa, a fim de fazer visitas ao ensino profissional francês e belga e depois contratar técnicos suíços para atuar na Escola Técnica Nacional. A missão, que se configura pedagógica inclusive por seu impacto na constituição do ensino técnico a partir da atuação dos profissionais estrangeiros, duraria três meses. Além disso, «a viagem foi realizada de navio do Lloyd Brasileiro até Lisboa. É possível que daí a Berna, Mange tenha prosseguido de trem» (Cunha, 2012, p. 393).

A missão foi decorrente do resultado do parecer de uma comissão que apresentou uma proposta específica para a contratação de técnicos suíços em detrimento de outros países que foram descartados, em parte por conta do contexto político e em parte por dificuldades técnicas, como a língua, por exemplo. Esta, inclusive, foi uma das «justificativas dadas por Capanema para não contratar professores estadunidenses» (Pedrosa e Santos, 2014, p. 327). A referida comissão fora formada em 1938, era composta por Mange, Lourenço Filho, León Renault, Góes Filho, Horácio da Silveira, Francisco Montojos e Rodolfo Fuchs, para levantar os problemas relativos ao ensino industrial no Brasil.

De conformidade com Machado, em 1940, como conclusão das discussões por uma comissão (composta por Montojos, Farias Góes e Rodolfo Fuchs), optou-se pela escolha de técnicos de apenas uma nacionalidade, alegando a necessidade de garantir a unidade dos métodos. Nestes termos, a comissão indicou que, naquele momento, os únicos países em condições de oferecer «elementos de valor» para estas ações seriam "os Estados Unidos, a Itália e a Suíça, a comissão opta por técnicos suíços. O descarte da Itália ocorre pela sua política interna, o que poderia dificultar os contratos» (Machado, 2010, p. 59). 
Em 1941 os professores selecionados por Mange na Suíça foram contratados. Cunha (2012) expõe as sugestões de Mange, em um relatório produzido, sobre o processo de viagem dos professores, o que fez com base na experiência com a ida à Europa:

[...] de trem até Lisboa e de lá ao Rio de Janeiro em navio brasileiro. A viagem pelos países ocupados e pela Península Ibérica seria difícil, pela quantidade de pessoas e pelas dificuldades trazidas pela guerra. Mange previa a necessidade de dois vagões ferroviários especiais, um para os contratados e suas famílias, outro para as bagagens. (Cunha, 2012, p. 393)

Os técnicos suíços chegaram em 1942 ao Rio de Janeiro. Dos 29 professores, 26 foram recontratados, no ano de 1944, para continuarem no Brasil, sendo a maioria para a Escola Técnica Nacional. A contratação de profissionais estrangeiros para esse setor no Brasil teve prosseguimento em 1942. Cunha (2012) detectou em uma carta de agosto de 1941 a presença de trâmites na direção da requisição pelo Ministério da Educação de técnicos norte-americanos. Fonseca (1962) afirma que Mange esteve nos Estados Unidos com o intuito de contratação no começo de 1942. A viagem, ocorrida no mês de janeiro, foi noticiada em uma edição do Correio Paulistano, na qual Mange, em entrevista, esclarece o objetivo de contratar 25 engenheiros ou técnicos «yankees». O viajante ainda registrou que se encontraria em Washington com Nelson Rockefeller, com quem estabeleceria "o roteiro» das futuras visitas para escolha dos candidatos. Ainda no periódico é possível acessar a via para chegar ao destino: de São Paulo para o Rio de Janeiro no avião da Vasp e da capital do país para Washington pela Panair.

Em abril de 1942, os estadunidenses enviaram uma correspondência diretamente a Mange requisitando preparação de indústria e mão de obra brasileira para a guerra, sendo formada uma comissão para analisar a questão (Cunha, 2012). Já em junho do mesmo ano, Mange enviou uma carta pedindo 36 funcionários dos Estados Unidos, um número maior do que o apontado como objetivo da viagem referida. Como conclusão desse processo, foram enviados ao Brasil o tímido número de 8 profissionais, contratados em 1943.

Esse foi também o ano em que ocorreu a i Conferência Interamericana de Ministros e Diretores de Educação, promovida no Panamá e a ser realizada em Havana, entre 25 de setembro e 4 de outubro de 1943. Segundo Fonseca (1961), Capanema; Lourenço Filho, então diretor do Instituto Nacional de Estudos Pedagógicos; Paulo Germano Hasslocker (Enviado Extraordinário e Ministro Plenipotenciário do Brasil em Havana) e o professor Francisco Clementino San Thiago Dantas representaram o Brasil.

Pedrosa e Santos (2014) destacam a reunião enquanto um elemento importante para o estabelecimento dos acordos entre os dois países nos anos seguintes tendo em vista a cooperação para o desenvolvimento da educação.

[...] em 1945, Vargas recebeu uma carta (provavelmente do embaixador do Brasil nos EUA) em que mencionava as articulações realizadas entre o coordenador de Negócios Interamericanos dos EUA, Kenneth Holland (o mesmo que assinaria o convênio que firmaria a Cbai em 1946), e o Brasil no tocante ao ensino profissional. Citava que o articulador estadunidense, por meio da Inter-American Education Fundation, pretendia definir um acordo com o Brasil. Acordo sobre o ensino profissional, bem como '[...] a criação de bolsas de estudo para aperfeiçoamento, nos Estados Unidos, de diretores, administradores e professores do ensino profissional [...]'. (Pedrosa e Santos, 2014, p. 330). 
Meses depois da carta (de abril), registra-se a ocorrência de uma outra viagem ${ }^{16}$, agora aos Estados Unidos, por Francisco Montojos. Embora não tenha sido observada na bibliografia consultada essa missão, optou-se por inseri-la por estar contida no processo de estruturação de um projeto que se desenvolvia entre os dois países.

Na condição de diretor da Divisão de Ensino Industrial, Montojos partiu em setembro e regressou em novembro de 1945, a bordo do «clipper» da Pan American World Airways. O objetivo era visitar escolas técnicas e estudar a possibilidade dos cursos de aperfeiçoamento para os professores brasileiros, «dentro das cláusulas do convênio de cooperação entre os países».

Em janeiro de 1946, Raul Leitão da Cunha, então Ministro da Educação, e Kenneth Holland, Presidente da Inter-American Education, Inc., representando cada país, assinaram o referido acordo, o qual previa a criação da Comissão Brasileira-Americana de Educação Industrial, CBAI. De com acordo com Pedrosa e Santos (2014), o período de vigência do acordo que instituiu a CBAl seria até 1948, mas foi prorrogado diversas vezes, até 1963, quando a Comissão foi extinta. Para Fonseca (1961), o maior benefício da Comissão foi a implantação do método TWI (Training Within Industry - Treinamento dentro da indústria). A CBAI, outrossim, se constituiu programa relevante quando se pensa nos marcos para pensar as viagens pedagógicas do ensino técnico, mais especificamente industrial, tendo em vista o serviço de promoção de cursos nos Estados Unidos a profissionais brasileiros.

\section{Considerações finais}

Sendo assim, a partir da pesquisa bibliográfica detectou-se algumas missões consideradas relevantes para o desenvolvimento do ensino técnico brasileiro de 1909 a 1946 e algumas repercussões que tiveram nas ideias para ensino técnico no Brasil. Algumas tiveram uma maior elucidação a partir da consulta a fontes do período, como é o caso da viagem de Roberto Mange em 1942 e a de Francisco Montojos em 1945.

Em síntese, foram inventariadas neste trabalho as viagens de João Luderitz (1909 e 1912 -ambas com destino à Europa e aos Estados Unidos); Roberto Mange (1929 Alemanha); Rodolfo Fuchs (1935 (?) - ao menos aos Estados Unidos); Lourenço Filho (1935 - Estados Unidos); -Antônio de Sá Pereira (1936 - Alemanha); Lourenço Filho, Francisco Montojos e León Renault (1936 - Itália, congresso); Rodolfo Fuchs (1938 Alemanha, e França); Francisco Montojos e Oscar Saraiva (1939 - Suíça); Roberto Mange (1940 - Bélgica, França e Suíça); Roberto Mange (1942 - Estados Unidos); Capanema e Lourenço Filho (1943 - Havana) e Francisco Montojos (1945 - Estados Unidos) ${ }^{17}$. Ressaltou-se, portanto, 13 partidas do Brasil.

Nota-se um certo equilíbrio quanto às visitas ligadas aos Estados Unidos e a regiões da Europa ao longo do recorte selecionado. Embora possa se perceber nitidamente a

(16) Viajantes. Diário de Notícias. Rio de Janeiro: 23 nov 1945. Disponível em: http://memoria.bn.br/DocReader/DocReader.aspx?bib=093718_02\&pesq=\%22Francisco\%20Montojos\%22 \&pasta=ano\%20194\&pagfis=25490 [Acesso em 22 nov. 2020].

(17) Os viajantes e lugares destacados nessa sistematização fazem referência aos que tiveram participação nas atividades relativas ao desenvolvimento do ensino profissional. 
notificação de viagens aos Estados Unidos a partir do momento em que o Brasil estabelece seu lado pró-Aliados.

A estadia no exterior durava dias ou mesmo anos e se mostram em muitos casos sendo uma partida do Brasil utilizada para se realizar as atividades necessárias no momento para o desenvolvimento do ensino técnico, mesmo quando se trata de pessoas não tão ligadas à área, como foi o caso de Sá Pereira. Nesse sentido, observou-se o ensino técnico brasileiro sendo pensado a partir de viagens de estudo, de participação em eventos, de sondagens e contratação, tendo implicação pedagógica tanto na situação da viagem quanto na repercussão (algumas, inclusive, bastante prolongadas), a partir de seus resultados.

Nesse sentido, vale também destacar o protagonismo de algumas figuras nas relações com o exterior. Muitas viagens foram realizadas por intelectuais que já tinham algum tipo de vínculo com o exterior, por relações de ascendência, pela anterior formação escolar no estrangeiro. Algumas das viagens se deram com a representação de delegações e outras foram individuais. O protagonismo de Roberto Mange no estabelecimento de acordos deve ser ressaltado, tendo em vista que parece ter encabeçado as negociações com os Estados Unidos.

Algumas das missões elencadas receberam um maior detalhamento quanto ao impacto que acarretaram no ensino técnico brasileiro, mas se entende que muito ainda deve ser feito nesse sentido. Com isso, espera-se que este inventário inicial, o qual certamente ainda poderá ser muito alterado no sentido de novas contribuições, possa auxiliar a elaboração de estudos que visem compreender a circulação de ideias e indivíduos ligados ao ensino técnico nacional do período.

\section{Referências}

Amorim, M. L. (2004) Da Escola Técnica de Curitiba à Escola Técnica Federal do Paraná: projeto de formação de uma aristocracia do trabalho (1942-1963). Tese doutoral. São Paulo, Universidade de São Paulo.

Boschetti, V. R. (2006) «O curso ferroviário da Estrada de Ferro Sorocabana». Revista Histedbr, 23, pp. 46-58.

Comissão Brasileiro-Americana de Educação Industrial (CBAI). Boletim da CBAI, v. II, n. 10. CBAl, Rio de Janeiro, 1948.

Cunha, L. A. (2000) O ensino de Ofícios nos primórdios da industrialização. São Paulo, Editora UNESP.

Cunha, L. A. (2012) «Professores e modelos estrangeiros para a Educação profissional brasileira (1936/1945)». Interseções: Revista de Estudos Interdisciplinares, vol. 14, n. 2, pp. 372-407.

Fonseca, C. S. da. (1961) História do Ensino Industrial no Brasil. (volume 1). Rio de Janeiro, ETN.

Fonseca, C. S. da (1962) História do Ensino Industrial no Brasil. (volume 2). Rio de Janeiro, ETN.

Fuchs, R. (1938) «O Congresso Internacional de Ensino Profissional de Berlim». Em Diário de Pernambuco. $\quad$ Recife: 71938. http://memoria.bn.br/DocReader/DocReader.aspx?bib=029033_11\&Pesq=\%22Rod olfo\%20Fuchs\%22\&pagfis=29940_[Acesso em 20 nov. 2020]. 
Machado, M. L. B. (2010) Racionalidade, trabalho e «harmonia social» - configurações do projeto de modernização brasileira e ensino industrial na Escola Técnica de Curitiba (1930-1960). Tese doutoral. Campinas, Universidade Estadual de Campinas.

Manfredi, S. M. (2002) Educação profissional no Brasil. São Paulo, Cortez.

Oliveira, M. de (2013) O Curso de Ferroviários da Estrada de Ferro Sorocabana (19311950). Dissertação (Mestrado). Sorocaba, Universidade de Sorocaba.

Pedrosa, J. G. (2015) «A atuação de Robert Auguste Edmond Mange (1885-1955) na constituição e na instituição do novo ensino industrial brasileiro nos anos 1930 e 1940». Educação \& Tecnologia, vol. 19, num. 2, pp. 47-58.

Pedrosa, J. G. e Duenhas, F. O. (2019) «A presença de Lourenço Filho na educação profissional brasileira dos anos 1950: trabalhos manuais e psicologia da aprendizagem». Multiverso: Revista Eletrônica do Campus Juiz de Fora-IF Sudeste MG, vol. 4.

Pedrosa, J. G. e Santos, O. G. (2014) «Agentes do ensino industrial no Brasil (1920-30-40) e suas referências internacionais: europeísmo e americanismo». Cadernos de história da educação, vol. 13, núm. 1, pp. 313-334.

Pronko, M. A. (2003) «A OIT nos primórdios da institucionalização do ensino técnicoprofissional». Boletim Técnico do Senac, vol. 29, núm. 1, pp. 40-51.

Queluz, G. L. (2000) Concepções de ensino técnico na República Velha (1909-1930). Curitiba, CEFET-PR.

Schwartzman, S.; Bomeny, H. M. B.; Costa, V. M. R. (2000) Tempos de Capanema. São Paulo \& Rio de Janeiro, Paz e Terra \& Editora da Fundação Getúlio Vargas.

Silva, M. F. W. da (2013) «Escola de Engenharia de Porto Alegre: Ensino técnico e política no Rio Grande do Sul (1899-1921)». En xxvii Simpósio Nacional de História. Natal. Anais [...]. Disponível em: http://www.eeh2012.anpuh-rs.org.br/resources/anais/27/ 1364957262_ARQUIVO_textoANPUH.pdf. [Acesso em 15 ago. 2020].

Viñao Frago, A. (2007) Viajes que educan. Em Mignot, A. C.; Gondra, J. G. (Org.) Viagens Pedagógicas. São Paulo, Cortez, pp. 15-38. 


\section{Els viatges educatius i l'ensenyament tècnic brasiler (1909-1946)}

Resum: L'objectiu d'aquest article és cartografiar els viatges pedagògics a l'exterior finançats amb la participació del govern brasiler amb propòsits relacionats amb l'estructuració de l'educació tècnica brasilera de 1909 a 1946, a partir del que s'ha trobat a la historiografia sobre el tema. Els marges temporals es refereixen a la implantació d'Escoles d'Aprenentatges Artesanals i de la Comissió BrasileraAmericana d'Educació Industrial, importants en la sistematització de l'ensenyament tècnic nacional. El concepte de viatges educatius corrobora la recerca bibliogràfica i documental, principalment en diaris de l'època -a través de l'Hemeroteca Digital brasilera-, però també en altres fonts com correspondència, fotografies. Així es detecten, doncs, els viatges a Europa i a Amèrica per tal de participar en esdeveniments temàtics, com el Congrés Internacional d'Educació Professional celebrat a Roma, el 1936, i/o visites tècniques, com a Alemanya, França, Suïssa i els Estats Units d'Amèrica, a més d'enquestes i execució efectiva de contractes. També s'intenta destacar als viatgers, el context i la durada de la missió i les repercussions ja assenyalades en la historiografia. Algunes d'elles es van dilucidar després de consultar fonts de l'època. L'estudi contribueix al camp de la història de l'educació professional, assegurant la circulació d'idees i models per a l'educació tècnica al Brasil.

Paraules clau: Viatges educatius, educació tècnica, intel·lectuals, Brasil.

\section{Les voyages pédagogiques et l'enseignement technique brésilien (1909- 1946)}

Résumé: L'objectif de cet article est d'inventorier les voyages pédagogiques à l'étranger financés par le gouvernement brésilien, avec des finalités liées à la structuration de l'enseignement technique brésilien de 1909 à 1946, à partir des informations collectées dans l'historiographie relative à cette question. Les étapes temporelles concernent l'implantation des Écoles d'apprentis et d'artisans et de la Commission brésilienne-américaine d'enseignement industriel, importantes dans la systématisation de l'enseignement technique national. Le concept de voyages pédagogiques corrobore la recherche bibliographique et documentaire, principalement dans les journaux de l'époque - par le biais de I'hémérothèque numérique brésilienne -, mais aussi dans d'autres sources comme les correspondances et les photographies. Des voyages en Europe et en Amérique ont été recensés en vue de la participation à des événements thématiques tels que le Congrès international de l'enseignement technique qui s'est tenu à Rome en 1936 et/ou de visites techniques, comme en Allemagne, en France, en Suisse et aux ÉtatsUnis, en plus des sondages et de la concrétisation effective de recrutements. On a cherché à mettre en évidence les voyageurs, le contexte et la durée de la mission, ainsi que les répercussions déjà signalées dans l'historiographie. Certaines d'entre elles ont été élucidées à partir de consultations de sources de la période. L'étude contribue au domaine de l'histoire de l'éducation professionnelle, en assurant la circulation des idées et des modèles pour l'enseignement technique au Brésil.

Mots-clés: Voyages pédagogiques, enseignement technique, intellectuels, Brésil.

\section{Educational trips and Brazilian technical experts (1909-1946)}

Abstract: The objective of this text is to explore the educational trips abroad financed by the Brazilian government for purposes related to the structuring of Brazilian technical education from 1909 to 1946. The timeframes refer to the implementation of the School of Apprentice Craftsmen and the BrazilianAmerican Commission for Industrial Education, which played key roles in the systematization of national technical education. The concept of educational trips emerges from bibliographical and documentary research, mainly in newspapers of the time (consulting the Hemeroteca Digital Brasileira) and also from other sources such as correspondence and photos. Trips to Europe and America were made to participate in thematic events, such as the International Congress on Professional Education held in Rome in 1936, and/or technical visits, such as visits to Germany, France, Switzerland and the US. The article focuses on the travellers, the context and duration of the mission and the repercussions already observed in the historiography. In some cases consultations of contemporary sources provided further information. The study contributes to the field of the history of professional education and underlines the importance of the circulation of ideas and models for technical education in Brazil.

Keywords: Educational trips, technical education, intellectuals, Brazil. 